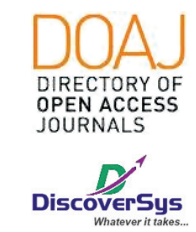

Published by DiscoverSys

\section{Prevalence of colorectal carcinoma based on microscopic type, sex, age and anatomical location in Sanglah General Hospital}

\author{
Michelle Anne Anthonysamy, ${ }^{1 *}$ Luh Putu lin Indrayani Maker, ${ }^{2}$ \\ I Made Gotra, ${ }^{2}$ Herman Saputra ${ }^{2}$
}

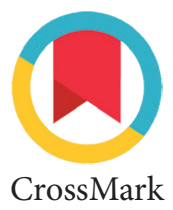

CrossMark

\begin{abstract}
Background: Colorectal carcinoma (CRC) is a disease in which epithelial cells in the colon or rectum become abnormal and divide without control, forming a mass called a tumor. Colorectal carcinoma is the fourth most frequent cancer in men after prostate and lung or bronchus cancers whereas in women is the third most frequent cancer after breast and lung or bronchus cancers. Colorectal cancer is a leading cause of cancer death worldwide, accounting for 693,900 deaths in 2012 and is the fourth most frequent cancer in men whereas in women is the third most frequent cancer. In Indonesia amount of rectal cancer were 1407 (5.67\%) and 990 cases (3.99\%) of colon cancer. Specifically in Denpasar, there are a total of 75 cases $(7.11 \%)$ of rectal cancer and 38 cases (3.60\%) of colon cancer in the year.

Aim: This study aims to know the prevalence of colorectal carcinoma based on microscopic type, sex, age and anatomical location in Sanglah General Hospital in Denpasar from January 2014 to January 2016.
\end{abstract}

Method: This study used descriptive retrospective research based on the secondary data from patients medical record which was taken at Sanglah General Hospital from January 2014 to January 2016. Population and sample amounted to 275 patients.

Results: This study shows that the highest prevalence of colorectal carcinoma was in a group of age $<50$ years old with 86 samples (31.3\%) and in a male with 163 samples (59.3\%). Adenocarcinoma has the highest prevalence of colorectal carcinoma with 270 samples (98.2\%). The rectum was the most frequent tumor location with 170 samples (61.8\%). In adenocarcinoma, the age group with the highest prevalence of CRC was $<50$ years with 85 samples (30.9\%). The highest prevalence of CRC based on anatomical location and age group was $<50$ years in the rectum with 57 samples (20.7\%).

Conclusion: Most of the CRC was found in age group $<50$ years, men had a higher risk to get colorectal carcinoma, adenocarcinoma is the most common microscopic type, and rectum was the most common site of colorectal carcinoma.
${ }^{1}$ Graduate Program in Medicine, Faculty of Medicine, Udayana University

${ }^{2}$ Department of Pathology Anatomy, Faculty of Medicine, Udayana University, Sanglah General Hospital

*Correspondence to: Graduate Program in Medicine, Faculty of Medicine, Udayana University Michelle Anne Anthonysamy, michy_annie@me.com

Received: 2018-02-21 Accepted: 2018-03-19 Published: 2020-03-27

Keywords: colorectal carcinoma, microscopic type, sex, age, anatomical location

Cite This Article: Anthonysamy, M.A., Maker, L.P.I.I., Gotra, I.M., Saputra, H. 2020. Prevalence of colorectal carcinoma based on microscopic type, sex, age and anatomical location in Sanglah General Hospital. Intisari Sains Medis 11(1): 272-276. D0I: 10.15562/ism.v11i1.171

\section{INTRODUCTION}

Colorectal carcinoma (CRC) is the fourth most frequent cancer in men after prostate and lung or bronchus cancers whereas in women is the third most frequent cancer after breast and lung or bronchus cancers. ${ }^{1}$ CRC is the leading cause of cancer death worldwide, accounting for 693,900 deaths in 2012. ${ }^{2}$ The incidence of colorectal carcinoma is different among different ethnic groups or population. About 141,210 new cases of colorectal carcinoma were diagnosed in the United States in the year 2011 with an estimated 49,380 deaths, representing approximately $9 \%$ of all newly diagnosed cancers and all cancer-related deaths. ${ }^{3}$ According to the reports from World Health Organization (WHO), the incidence of CRC is drastically rising in many Asian countries, i.e., Japan, China, Korea, and Singapore. ${ }^{4}$ Particularly, the IARC (International Agency for Research on Cancer) publishes its sets of estimates of global cancer incidence and mortality through the GLOBOCAN project which is the most recent one being from 2012. Based on estimates of GLOBOCAN, there are 746,000 cases, $10.0 \%$ of the total CRC in men and in women there are 614,000 cases, $9.2 \%$ of the total worldwide. Almost $55 \%$ of the cases arise in greater developed areas. There is extensive geographical variation in incidence across the world and their patterns are very similar in male and female: incidence rates differ ten-fold in both sexes around the world, in Australia/New Zealand it is the highest estimated rate with (ASR 44.8 and 32.2 per 100,000 in men and women respectively), whereas it is the lowest in Western Africa (4.5 and 3.8 per 100,000). Based on the histopathologic data of cancer in Indonesia, there are 1407 cases of rectal cancer and 990 cases of colon cancer which is $5.67 \%$ and $3.99 \%$ respectively in the year $2011 .^{5}$

Based on the CRC incidence rates and proportion by tumor subsite in the USA from the year 
2006 to 2010, the most common tumor location is the proximal colon (42\%), followed by the rectum (28\%). The anatomical location distribution related to their sex. For proximal tumors, women have a higher percentage (46\%) compared with men $(38 \%)$, and in rectal tumors, women have a lower percentage with $24 \%$ compared to male with $31 \%$. Besides that, there are also differences in anatomical location distribution using age at diagnosis; there is a decrease in rectal tumors with advancing age whereas proximal tumors have a notable increase. About 56\% of colorectal carcinomas in women aged 50 years and older are in the proximal colon, compared with $26 \%$ in those aged younger than 50 years. For rectal cancer, the median age at diagnosis is younger (63 years in men and 65 years in women) compared to colon cancer with 69 years in men and 73 years in women. ${ }^{6}$ There is no significant study on the incidence rate of the anatomical location of colorectal carcinoma based on age and sex in Indonesia specifically Denpasar.

Anatomical subsites were characterized based on the third release of the International Classification of Diseases for Oncology. Proximal colon includes the cecum, ascending colon; transverse colon includes the hepatic and splenic flexures; distal colon consists of the descending colon and sigmoid; and rectum as consists of the rectum and rectosigmoid junction. ${ }^{7}$ There are 4 parts in which are ascending colon, transverse colon, descending colon and sigmoid colon. The ascending colon begins at the cecum, continues upward against the posterior abdominal wall, inferior to the liver, and then turns to the left sharply at the hepatic flexure. The transverse colon is the longest and most movable part, it is suspended by a fold of peritoneum and sags in the middle, below the stomach; near the spleen, it turns abruptly downward at the splenic flexure. The descending colon is a mostly vertical section that makes an S-shaped curve near its lowest portions, at the sigmoid flexure. The sigmoid colon is the final portion which is $15 \mathrm{~cm}$ long which becomes the rectum. The sigmoid colon lies posterior to the urinary bladder. The rectum is next to the sacrum and resembles its curvature. The rectum ends about $5 \mathrm{~cm}$ below the tip of the coccyx becoming the anal canal. $^{8}$

The classifications of histologic types of colorectal carcinoma according to WHO are adenocarcinoma (cribriform comedo-type adenocarcinoma, medullary carcinoma, micropapillary carcinoma, mucinous adenocarcinoma, serrated adenocarcinoma, signet-ring cell carcinoma), adenosquamous carcinoma, spindle cell carcinoma, squamous cell carcinoma and undifferentiated carcinoma. ${ }^{1}$ Most colorectal carcinomas are adenocarcinomas of which mucinous constituting about $10 \%$ whereas signet ring cell carcinoma comprising $1 \%-2.4 \%$ of the total adenocarcinoma cases. Mucinous adenocarcinomas are defined histologically by way of the presence of abundant extracellular mucin, with greater than $50 \%$ of the tumor mass being mucinous. For signet ring carcinomas, the intracellular mucin will be pushing the nucleus to one side. ${ }^{9}$

CRC normally grows gradually, over a period of 10 to 20 years such as development of malignancy from adenomas. ${ }^{10}$ The majority of CRC progress from adenoma that is known as pre-cancerous condition where a polyp grows on the inward coating of the colon or rectum. Adenomas develop from glandular cells that help lubricate colorectal by producing mucus. ${ }^{11}$ As the adenoma increases the probability that the adenoma will develop into carcinoma is higher. ${ }^{9}$

\section{METHODS}

The study was a retrospective design to determine the prevalence of microscopic type, sex, age and anatomical location of colorectal carcinoma patients. Samples in this study are all of the data of colorectal carcinoma patients in Sanglah General Hospital, Denpasar from January 2014 until January 2016 that contains the complete medical register based on the variable studied. The sampling method applied consecutive sampling where researchers choose a sample based on subjective and practical considerations - in this case, the complete medical records. The variables studied in this study were microscopic types according to WHO classifications 2010 (adenocarcinoma [cribriform comedo-type adenocarcinoma, medullary carcinoma, micropapillary carcinoma, mucinous adenocarcinoma, serrated adenocarcinoma, signet-ring cell carcinoma], adenosquamous carcinoma, spindle cell carcinoma, squamous cell carcinoma, and undifferentiated carcinoma), sex (male or female), age group of $<50,51-60,61-70$ and $>70$ years, and anatomical location of tumor.

Colorectal carcinoma is the development of cancer from the colon or rectum which are parts of large intestine due to the abnormal growth of mucosal epithelial cells. ${ }^{12}$ An analysis of existing data is conducted in the Pathology Anatomy Department to the prevalence of colorectal carcinoma based on microscopic type, age, sex and anatomical location. The location of colorectal carcinoma at the time of diagnosis, such as proximal (cecum, ascending colon, and transverse colon, hepatic, and splenic flexures); distal (descending colon and sigmoid); and rectum (rectum and rectum sigmoid junction). 


\section{RESULTS AND DISCUSSION}

The total number of samples that were obtained from January 2014 to January 2016 is 275 samples. The data of each variable is presented in table form including age, sex, anatomical location and microscopic types. The average age of the patient is 55.85 years with the median value of 57 years. The youngest sample age is 19 years old while the oldest sample is 95 years old. For the sex of the samples, 163 samples (59.3\%) were male and $112(40.7 \%)$ samples were female (Table 1 and 2).

Based Table 3, the highest frequency of colorectal carcinoma(CRC) were found in the age group of $<50$ years with 86 samples $(31.3 \%)$ followed by 51-60 years with 83 samples (30.2\%), 61-70 years with 66 samples (24\%) and the age

Table 1 Proportion of Colorectal Carcinoma patients in Sanglah General Hospital from January 2014 to January 2016 based on age

\begin{tabular}{lcc}
\hline Age Group (years old) & Frequency & Percentage (\%) \\
\hline$<50$ & 86 & 31.3 \\
$51-60$ & 83 & 30.2 \\
$61-70$ & 66 & 24 \\
$>70$ & 40 & 14.5 \\
\hline
\end{tabular}

Table 2 Proportion of Colorectal Carcinoma patients in Sanglah General Hospital from January 2014 to January 2016 based on age group and sex

\begin{tabular}{ccccccccc}
\hline Age & \multicolumn{2}{c}{$<\mathbf{5 0}$} & \multicolumn{2}{c}{$\mathbf{5 1 - 6 0}$} & \multicolumn{2}{c}{$\mathbf{6 1 - 7 0}$} & \multicolumn{2}{c}{$>\mathbf{7 0}$} \\
\hline Gender & $\mathbf{N}$ & $\mathbf{\%}$ & $\mathbf{N}$ & $\mathbf{\%}$ & $\mathbf{N}$ & $\mathbf{\%}$ & $\mathbf{N}$ & $\mathbf{\%}$ \\
\hline Male & 47 & 17.1 & 50 & 18.2 & 40 & 14.5 & 26 & 9.4 \\
Female & 39 & 14.2 & 33 & 12.0 & 26 & 9.5 & 14 & 5.1 \\
\hline
\end{tabular}

Table 3 Proportion of Colorectal Carcinoma patients in Sanglah General Hospital from January 2014 to January 2016 based on microscopic types

\begin{tabular}{lcc}
\hline Microscopic types & Frequency & Percentage (\%) \\
\hline Adenocarcinoma & 270 & 98.2 \\
Cribriform comedo-type & 0 & 0 \\
adenocarcinoma & 0 & 0 \\
Medullary carcinoma & 0 & 0 \\
Micropapillary carcinoma & 19 & 7.0 \\
Mucinous adenocarcinoma & 0 & 0 \\
Serrated adenocarcinoma & 7 & 2.5 \\
Signet ring cell carcinoma & 0 & 0 \\
Adenosquamous carcinoma & 0 & 0 \\
Spindle cell carcinoma & 5 & 1.8 \\
Squamous cell carcinoma & 0 & 0 \\
Undifferentiated carcinoma & & \\
\hline
\end{tabular}

group of $>70$ years with 40 samples $(14.5 \%)$. The prevalence of CRC in the age group of $<50$ is increasing which is supported in the study by Murphy, Lund and Sandler (2017). ${ }^{13}$ From the early 1990s, incidence rates have increased in this population (ages 20-49 years), from 8.5 per 100,000 in 1992 to 10.7 per 100,000 in 2013 , a $26 \%$ increase. However, the main reason behind increasing young-onset CRC incidence is not well understood. It is noteworthy that young-onset colorectal incidence increased, whereas CRC risk factors, for example sedentary lifestyle, obesity, and diabetes mellitus, were either common or increasing. About $13 \%$ to $18 \%$ increase in CRC risk is associated with every 5-unit increase in body mass index. Approximately $38 \%$ increase in colon cancer risk and a $20 \%$ increase in rectal cancer is associated with diabetes mellitus. However, these risk factors alone are not the reason behind the observed trends in young-onset CRC as they are common or increasing in older age groups in which CRC incidence decreased. ${ }^{11}$

One of the characteristic of hereditary CRC syndromes is young age of CRC onset and these syndromes contribute disproportionately to young-onset CRCs. According to Chang et al (2012) from a consecutive series of more than 1100 CRCs, 75 CRCs in patients $<40$ years and found that $22 \%$ of these tumors were because of hereditary syndromes where $17 \%$ is because of abnormalities in DNA mismatch repair and 5\% is because of other genetic syndromes. ${ }^{11}$ The age group $>50$ years has 189 samples $(68.7 \%)$ which is supported from a study by Molenaar, Radivoyevitch and Wilmink (2017) stating 90\% of CRC occur at age above 50 years. This may occur due to the accumulated DNA mutations in colonic wall cells along with age, as well as a decrease in the body's immune system, which increases with age, which is marked by decreased immunoglobulin production, lymphocyte configuration and reactions in the fight against reduced infection and decreased ability the body's immune system in recognizing foreign objects that enter the body. ${ }^{14}$

As seen in Figure 3, 163 samples (59.3\%) were male and $112(40.7 \%)$ samples were female. These results are consistent with the study of Wahidin et al (2012) which suggests that men are more likely to develop colorectal carcinoma (4.13 per 100,000) than women $(3.15$ per 100,000$)$. According to Lin et al (2013), estradiol levels play a role in the number of occurrences of colorectal carcinoma in men. Estradiol in normal amounts function in spermatogenesis and fertility. However, excessive amounts of estradiol inhibit gonadotropin protein secretion such as LH which further reduces testosterone secretion. The high amount of testosterone 
Table 4 Proportion of Colorectal Carcinoma patients in Sanglah General Hospital from January 2014 to January 2016 based on anatomical location

\begin{tabular}{lcc}
\hline Anatomical Location & Frequency & Percentage (\%) \\
\hline $\begin{array}{l}\text { Proximal (cecum, ascending colon, and } \\
\text { transverse colon, hepatic and splenic }\end{array}$ & 46 & 16.7 \\
flexures). & & \\
Distal (colon descending colon and sigmoid) & 59 & 21.5 \\
Rectum (rectum and rectosigmoid) & 170 & 61.8 \\
\hline
\end{tabular}

Table 5 Microscopic types and anatomical location of Colorectal Carcinoma patients in Sanglah General Hospital from January 2014 to January 2016 based on age group

\begin{tabular}{|c|c|c|c|c|c|c|c|c|}
\hline \multirow[b]{2}{*}{ Age } & \multicolumn{2}{|c|}{$<50$} & \multicolumn{2}{|c|}{$51-60$} & \multicolumn{2}{|c|}{$61-70$} & \multicolumn{2}{|c|}{$>70$} \\
\hline & $\mathbf{N}$ & $\%$ & $\mathbf{N}$ & $\%$ & $\mathbf{N}$ & $\%$ & $\mathbf{N}$ & $\%$ \\
\hline \multicolumn{9}{|l|}{ Microscopic Types } \\
\hline Adenocarcinoma & 85 & 30.9 & 80 & 29.1 & 67 & 24.4 & 38 & 13.8 \\
\hline $\begin{array}{l}\text { Adenosquamous } \\
\text { carcinoma }\end{array}$ & 0 & 0 & 0 & 0 & 0 & 0 & 0 & 0 \\
\hline Spindle cell carcinoma & 0 & 0 & 0 & 0 & 0 & 0 & 0 & 0 \\
\hline Squamous cell carcinoma & 1 & 0.4 & 2 & 0.7 & 0 & 0 & 2 & 0.7 \\
\hline Undifferentiated carcinoma & 0 & 0 & 0 & 0 & 0 & 0 & 0 & 0 \\
\hline \multicolumn{9}{|l|}{ Anatomical Location } \\
\hline $\begin{array}{l}\text { Proximal (cecum, } \\
\text { ascending colon, and } \\
\text { transverse colon, hepatic } \\
\text { and splenic flexures) }\end{array}$ & 13 & 4.7 & 17 & 6.2 & 10 & 3.6 & 6 & 2.2 \\
\hline $\begin{array}{l}\text { Distal (colon descending } \\
\text { colon and sigmoid) }\end{array}$ & 16 & 5.9 & 18 & 6.5 & 17 & 6.2 & 8 & 2.9 \\
\hline $\begin{array}{l}\text { Rectum (rectum and } \\
\text { rectosigmoid) }\end{array}$ & 57 & 20.7 & 48 & 17.5 & 39 & 14.2 & 26 & 9.5 \\
\hline
\end{tabular}

has been shown to be associated with a reduced risk of colorectal carcinoma. ${ }^{15}$ Based on Table 4, male has the highest frequency compared to female in all the age group. The incidence in men by about $20 \%$ more often than women. ${ }^{16}$

As seen in Table 5, 270 samples (98.2\%) were adenocarcinoma and 5 samples (1.8\%) were squamous cell carcinoma. For the subtype of adenocarcinoma, 19 samples (7.0\%) were mucinous adenocarcinoma and 7 samples (2.5\%) were signet ring cell carcinoma. This finding is supported in a study by Tan et al (2015) stating that adenocarcinoma is the most common microscopic type of colorectal carcinoma (CRC) with more than $95 \%$ of CRC cases. ${ }^{17}$ Mucinous adenocarcinoma and signet-ring cell carcinoma are rare, with mucinous adenocarcinoma accounting for about $10-15 \%$ of CRC cases and signet ring cell accounting for about $0.1-2.4 \%$ of CRC cases. In 1000 CRC cases, the incidence of squamous cell carcinoma is about 0.10 to $0.25 .^{18}$
Based on Table 6, the highest frequency of colorectal carcinoma with 170 samples $(61.8 \%)$ was at rectum (rectum and rectosigmoid), 59 samples $(21.5 \%)$ at distal (colon descending colon and sigmoid) and 46 samples (16.7\%) at proximal (cecum, ascending colon, and transverse colon, hepatic and splenic flexures). However, the results of this study were different from American Cancer Society where the highest percentage of distribution of tumor sites was proximal colon with $41 \%$ and rectum with only $28 \% .{ }^{19}$ So in this study the rectum is the most common location of colorectal carcinoma and has a greater tendency for the occurrence of colorectal carcinoma. This is associated with more rectal function of stool and defecation, where it is known that one of the environmental factors that can trigger cancer is food. Consuming foods high in pure carbohydrates can increase the risk of colorectal carcinoma. This results in changes in faecal flora and bile salt degradation changes or the breakdown of proteins and fats, some of which are carcinogenic. ${ }^{20} \mathrm{~A}$ low-fiber diet also leads to the concentration of faeces and increased stool transits. Thus resulting in contact between carcinogenic substances with the colon mucosa and rectum being way longer. ${ }^{21}$

Based on table 7 , in adenocarcinoma, 85 samples $(30.9 \%)$ for age $<50$ years, 80 samples $(29.1 \%)$ for age 51-60 years, 67 samples (24.4\%) for age 61-70 years and 38 samples $(13.8 \%)$ for age $>70$ years. In squamous cell carcinoma, 1 sample $(0.4 \%)$ for age $<50$ years, 2 samples $(0.7 \%)$ for age $51-60$ years and 2 samples $(0.7 \%)$ for age $>70$ years. In the study by Benmoussa et al (2013) which involved 133 patients with colon cancer in Morocco, it was reported that mucinous adenocarcinoma and signet ring cells carcinoma were more common in younger age groups ( $<50$ years) than in the elderly ( $>50$ years) $(18.5 \%$ vs. $5.1 \%)$. However, different conclusions were reported in a separate study, which reported that there was no significant difference in grade and tumor histology among elderly patients and younger patients. ${ }^{22}$ Squamous cell carcinoma is a rare entity and only case reports and relatively small case. Based on the study by Dyson and Draganov (2009), in about 1000 CRC cases, the incidence of squamous cell carcinoma is approximately 0.10 to 0.25 . Those between the ages of 39 to 93 years old, with a mean age of 57 years appears to be affected by squamous cell carcinoma more often. ${ }^{18}$

The highest prevalence of CRC for age $<50$ years is in the rectum (rectum and rectosigmoid) with 57 samples (20.7\%) followed by distal (colon descending colon and sigmoid) with 16 samples (5.9\%) and proximal (cecum, ascending colon, and transverse colon, hepatic and splenic flexures) with 13 samples (4.7\%). For age 51-60, the highest 
prevalence of CRC is also in rectum with 48 samples (17.5\%) followed by distal with 18 samples (6.5\%) and proximal with 17 samples (6.2\%). For age 61-70, the highest prevalence of CRC is also in rectum with 39 samples (14.2\%) followed by distal with 17 samples $(6.2 \%)$ and proximal with 10 samples (3.6\%). For age $>70$, the highest prevalence of CRC is in rectum with 26 samples (9.5\%) followed by distal with 8 samples (2.9\%) and proximal with 6 samples (2.2\%). These findings are supported by a study stating that there are differences in subsite distribution by age at diagnosis, with a notable increase in proximal tumors for those $>50$ years compared to $<50$ years and decrease in rectal tumors with advancing age. For example, 56\% of colorectal carcinomas in women aged 50 years and older are in the proximal colon, compared with $26 \%$ in those aged younger than 50 years. An increasing incidence rate was also observed for patients with rectal cancer aged 35 to 49 years. $^{6}$

\section{CONCLUSION}

The lowest prevalence of CRC based on the age is more than 70 years, and the highest is less than 50 years. The highest prevalence based on gender is male compared to the women. Besides that, among all age group, the male has the highest prevalence for the age 51-60. According to the microscopic type and the anatomical location, adenocarcinoma and the rectum are the most frequent feature. For people below the age of 50, they should apply the early detection of CRC and advised to perform a colonoscopy or biopsy as it is good to receive an action to prevent the disease from progressing to more severe stages.

\section{ACKNOWLEDGMENT}

I would like to acknowledge dr. Gede Wirata, S.Ked, M.Biomed for the beneficial review prior to submission in this journal as well as much corrections with regard to the author guideline.

\section{REFERENCES}

1. Bhandari, A., Woodhouse, M., and Gupta, S. Colorectal cancer is a leading cause of cancer incidence and mortality among adults younger than 50 years in the USA: a SEERbased analysis with comparison to other young-onset cancers. Journal of Investigative Medicine 2016; 65(2): 311-31.

2. Bosman F. WHO classification of tumours of the digestive system. 4th ed. Lyon, France.: IARC Press; 2010.

3. Fleming, M., Ravula, S., Tatishchev, S. and Wang, H. Colorectal carcinoma: Pathologic aspects. Journal of Gastrointestinal Oncology 2012; 3(3): 153-173.

4. Ferlay, J., Shin, H., Bray, F., Forman, D., Mathers, C. and Parkin, D. Estimates of worldwide burden of cancer in 2008: GLOBOCAN 2008. International Journal of Cancer 2010; 127(12): 2893-2917.
5. Direktorat Jendral Pelayanan Medik. 2012. Kanker di Indonesia Tahun 2011. Data Histopatologik. Jakarta: Department Kesehatan R.I

6. Siegel, R., DeSantis, C. and Jemal, A. Colorectal cancer statistics, 2014. CA: A Cancer Journal for Clinicians 2014; 64(2): 104-117.

7. Seer.cancer.gov. (2017). SEER ICD-O-3 Coding Materials. [online] Available at: http://seer.cancer.gov/icd-o-3/.

8. Moini, J. 2015. Anatomy and physiology for health professionals. 2nd ed. Burlington: Jones \& Bartlett Publishers.

9. Stewart, S., Wike, J., Kato, I., Lewis, D. and Michaud, F. A population-based study of colorectal cancer histology in the United States, 1998-2001. Cancer 2006; 107(S5): 1128-1141.

10. Haggar, F. and Boushey, R. Colorectal Cancer Epidemiology: Incidence, Mortality, Survival, and Risk Factors. Clinics in Colon and Rectal Surgery 2009; 22(04): 191-197.

11. Ahnen, D., Wade, S., Jones, W., Sifri, R., Mendoza Silveiras, J., Greenamyer, J., Guiffre, S., Axilbund, J., Spiegel, A. and You, Y. The Increasing Incidence of YoungOnset Colorectal Cancer: A Call to Action. Mayo Clinic Proceedings 2014; 89(2): 216-224.

12. Goodman, B. Insights into digestion and absorption of major nutrients in humans. AJP: Advances in Physiology Education 2010; 34(2): 44-53.

13. Murphy, C., Lund, J. and Sandler, R.. Young-Onset Colorectal Cancer: Earlier Diagnoses or Increasing Disease Burden?. Gastroenterology 2017; 152(8): 1809-1812.

14. Molenaar, R., Radivoyevitch, T. and Wilmink, J. RE: Colorectal Cancer Incidence Patterns in the United States, 1974-2013. JNCI: Journal of the National Cancer Institute; 2017: 109(8)

15. Lin, J., Zhang, S., Rexrode, K., Manson, J., Chan, A., Wu, K., Tworoger, S., Hankinson, S., Fuchs, C., Gaziano, J., Buring, J. and Giovannucci, E. (2013). Association Between Sex Hormones and Colorectal Cancer Risk in Men and Women. Clinical Gastroenterology and Hepatology 2013; 11(4): 419-424.e1.

16. Shan Lin, H. and Turner, D. The Benefit and Tolerability of Adjuvant Chemotherapy in Elderly Stage III Colon Cancer Patients: A 3 Year Retrospective Audit. Journal of Gerontology \& Geriatric Research 2016; 5(4).

17. Tan, Y., Fu, J., Li, X., Yang, J., Jiang, M., Ding, K., Xu, J., Li, J. and Yuan, Y. A Minor $(<50 \%)$ Signet-Ring Cell Component Associated with Poor Prognosis in Colorectal Cancer Patients: A 26-Year Retrospective Study in China. PLOS ONE 2015; 10(3): 1-14.

18. Dyson, T. and Draganov, P. Squamous cell cancer of the rectum. World Journal of Gastroenterology 2009; 15(35): 4380 .

19. Siegel, R., Miller, K., Fedewa, S., Ahnen, D., Meester, R., Barzi, A. and Jemal, A. Colorectal cancer statistics, 2017. CA: A Cancer Journal for Clinicians 2017: 67(3): 177-193.

20. Wirata, G., Santoso, P.N.C., Dewantari, P.A.U. 2018. Microstructural aspect of pineal body: the population of pinealocytes. Intisari Sains Medis 9(1): 25-30. DOI: 10.1556/ism.v9i1.151

21. Nistal, E., Fernández-Fernández, N., Vivas, S. and Olcoz, J. Factors Determining Colorectal Cancer: The Role of the Intestinal Microbiota. Frontiers in Oncology 2015; 5: 1-10.

22. Benmoussa, A., Zamiati, S., Badre, W., Wakadi, A., Bennani, N., Tahiri Jouti, N. and Nadifi, S. Colorectal cancer: Comparison of clinicopathologic features between Moroccans patients less than 50 years old and older. Pathologie Biologie 2013; 61(3): 117-119.

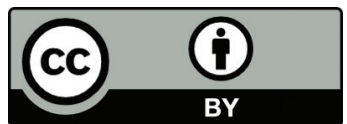

This work is licensed under a Creative Commons Attribution 